\title{
Survey on micturition disorders, surgical procedures and therapeutic approaches in patients treated for gynecologic cancers in clinical settings
}

\author{
Mizue Inoue* \\ School of Nursing, Fukushima Medical University, Japan
}

\begin{abstract}
Objective: To elucidate the current status of micturition disorders in postoperative patients treated for gynecologic cancer, surgical procedures, history of their multidisciplinary treatments, and therapeutic approaches.

Methods: Survey population: Ambulatory patients who received gynecologic cancer treatment at best hospitals for cancer treatments in the Tohoku district and provided informed consent to participate in the survey. 2. Survey method: Questionnaire-based survey. Survey items: 1) Basic attributes (age, name of disease, BMI, and childbirth experience), treatments (surgical procedures, history and therapeutic approaches of multidisciplinary treatments), Performance Status (PS): preoperative and postoperative incontinence, measures to be taken and 2) Core lower urinary tract symptom score (Core LUTS Score CLSS, hereafter CLSS) were evaluated.

Results: A total of 80 patients were included in the analysis population (the response rate: $93.0 \%$ ). Patients with metastatic cancer and those who underwent cervical cone biopsy were excluded from the study. Basic attributes: For surgical procedures in the age category, the population of $<50$ years old had total hysterectomy in 6 patients $(7.5 \%)$, modified radical hysterectomy in 6 patients $(7.5 \%)$ and radical hysterectomy in 16 patients $(20.0 \%)$ whereas the population of $\geq 70$ years old had total hysterectomy in 2 patients $(2.5 \%)$, modified radical hysterectomy in 3 patients $(3.8 \%)$ and radical hysterectomy in 4 patients $(5.0 \%)$, indicating that the rate of surgical intervention was significantly higher in the older population $(\chi 2=11.67, \mathrm{P}<0.05)$. For other basic attributes, no significant differences were noted.

Micturition disorders: For history of multidisciplinary treatments and dysuria of CLSS category, 17 patients (21.3\%) without multidisciplinary treatments and 58 patients $(72.5 \%)$ with multidisciplinary treatments answered with "No experience" for urethral pain. This demonstrates that the incidence of urethral pain was significantly lower in patients with multidisciplinary treatments $(\chi 2=14.06, \mathrm{p}<0.001)$. For multidisciplinary treatments and lower abdominal pain of CLSS category, among patients on chemotherapy, for urethral and lower abdominal pain 42 patients (52.5\%) answered with "No experience", whereas was 0 patients $(0.0 \%)$ answered with "Experienced", demonstrating a significant difference is associated with multidisciplinary treatments $($ lower abdominal pain: $\chi 2=11.27, \mathrm{p}<0.01$; dysuria: $\chi 2=14.06, p<0.003)$. No significant differences in the other CLSS items were noted for history of multidisciplinary treatments and therapeutic approaches of multidisciplinary treatments.

Conclusion: The clinical pictures of micturition disorders in patients undergoing gynecologic cancer treatment showed the trend that many patients experience stress incontinence and slow urine stream, and devices such as incontinence pad are often used for incontinence management, only about $1 \%$ of them is doing pelvic floor muscle exercise by themselves. Moreover, no associations were noted between development of the lower urinary tract symptom and surgical procedures, history of multidisciplinary treatments or therapeutic approaches of multidisciplinary treatments. However, as many as $80 \%$ of the patients rated their quality of life (QOL) relating to voiding symptoms as dissatisfied.
\end{abstract}

\section{Introduction}

In recent years, cancer treatment has incorporated multidisciplinary approaches where surgical therapies, chemotherapies, and radiotherapies play important roles as three major cancer treatments. Meanwhile these therapeutic interventions are similarly provided postoperatively for gynecologic cancers (e.g., uterine cancer, uterine corpus cancer and ovarian cancer), elimination disorders are often associated with surgery and multidisciplinary treatments, affecting many patients.

In classification of treatment types, the incidence of surgery-related micturition disorders varies ranging 8 to $80 \%$ [1], predominantly reported on radical hysterectomy. Pelvic floor muscle exercise can be an effective tool in improving symptoms associated with micturition disorders attributable to pelvic nerve damage, but urinary symptoms may stabilize one year after operations [2]. Pollakiuria and dysuria can be associated with radiotherapy (JASTRO, 2011). For chemotherapy, taxane anticancer drugs used can affect the autonomic nervous system and can cause micturition disorders [3]. Moreover, causes of micturition disorders are complicated as represented by e.g. hypesthesia secondary to exacerbation of peripheral nerve disorders affected by multiple-dose of anticancer drugs and cystitis associated with susceptibility by bone marrow suppression, and adverse effects. Ideally, the improvement of

Correspondence to: Mizue Inoue, School of Nursing, Fukushima Medical University, Japan, Tel: 0245471841; Fax: 0245471841; E-mail: i-mizue@fmu.ac.jp

Key words: gynecologic cancer, postoperative, multidisciplinary cancer care, micturition disorder

Received: December 08, 2017; Accepted: December 19, 2017; Published: December 22, 2017 
micturition disorders should be addressed by physicians of gynecology and urology and nurses at an early stage of disease, but no guidelines have not been established to address the complex factors contributing to disease onset and have not been exhaustively reviewed. Medical practice prioritizes radical cures against cancers, the underlying diseases rather than micturition disorders, and hence micturition disorders are not fully addressed.

Moreover, the onset of gynecologic cancers is common for patients in late middle age who normally have socially crucial responsibilities, and they must live their life with micturition disorders after hospital discharge. It is one of the factors contributing to lower QOL [4]. Nonetheless, due to disorders of the excretion organ they cannot easily confide their own perceived troubles and anxieties, which presumably are an extremely serious burden on mental health. The author actually feels needs for nursing cares at an early stage for patients who develop micturition disorders following multidisciplinary treatments for gynecologic cancers. Despite the needs, only few studies have been published on patients with micturition disorders associated with multidisciplinary care for gynecologic cancer, and the current status of the disorders is unclear.

In this context, the present research aimed at elucidating the current status of micturition disorders in patients who received gynecologic cancer treatment in terms of surgical procedures and history and types of multidisciplinary care.

\section{Research method}

\section{Population}

The survey, conducted from April to October 2017, involved ambulatory patients with history of multidisciplinary treatments for gynecologic cancer in best hospitals for cancer treatment in the Tohoku district. All patients provided informed consent on the survey.

\section{Survey descriptions}

\section{Questionnaire-based survey was conducted.}

1) Basic attributes (age, name of disease, BMI and childbirth experience), treatments (surgicalprocedures, historyofmultidisciplinary treatments, and therapeutic approach of multidisciplinary treatments), Performance Status (PS): preoperative and postoperative incontinence and measures to be taken)

\section{2) Core lower urinary tract symptom score (CLSS)}

CLSS comprised of 10 items, i.e. urinary frequency, urinary urgency, urge incontinence, stress incontinence, slow urine stream, abdominal straining during voiding, feeling of residual urine, lower abdominal pain, urethral pain in daytime and nighttime were rated on a 4-point scale, which was designed to understand extensively issues related to voiding. The score system is not intended to identify specific diseases/conditions and it is considered as an effective instrument for fundamental assessment of undiagnosed micturition disorders, and the reliability and justification of this system are presented [5-7].

\section{Analysis method}

The analysis entailed calculation of the basic statistics for predefined items sorted largely by three groups, surgical procedures, and history of multidisciplinary treatment and therapeutic approach of multidisciplinary treatments. For categories of BMI, age, childbirth experience, preoperative and postoperative incontinence and CLSS, the choices of answers provided on the questionnaire, "No experience" was included in "No experience (0)", whereas "Occasionally" / "Sometimes", and "Always" were included in "Experienced (1)" for analysis using $\chi 2$ test. Data analysis employed statistical software (SPSS23.0 J for Windows).

\section{Ethical considerations}

The present research was conducted after approval by Ethical Committee of Fukushima Medical University (No. 3036). The participants provided informed consent after verbal and written explanations as follows; the objectives and methodology of the present research, subjects are voluntary participants, subject's refusal of or withdrawal from participation does not cause any disadvantage to subjects.

\section{Results}

The analysis population included 80 patients among 86 patients who provided their informed consents, excluding patients with metastatic cancer and those who underwent cervical cone biopsy (response rate 93.0\%).

1. Basic attributes, preoperative and postoperative micturition disorders and measures against them (Tables 1 and 2)

The mean age of the analysis population was $55.0 \pm 11.5$ years old (range: 33 to 78 years old). In the category of age, 43 patients $(53.8 \%$, highest number) are included in the 50-to-69-year-old population, 18 patients $(22.5 \%)$ in $<50$-year-old population and 9 patients $(11.3 \%)$ in $\geq 70$-year-old population. On the site of disease, cervical cancer was found in 29 patients (36.3\%), uterine corpus cancer in 28 patients (35.0\%), ovarian cancer in 20 patients $(25.0 \%)$ and others (carcinomas) in 3 patients (3.8 patients). Mean BMI was $23.6 \pm 5.5$, and 14 patients $(17.5 \%)$ are "Lean", 39 patients (48.8\%)"Normal", and 27 patients (18.0\%) "Obese". For childbirth experience, 23 patients $(28.7 \%)$ answered with "No experience", meanwhile 57 patients $(71.3 \%$, the highest number) responded with "Experienced". 31 patients $(38.8 \%)$ experienced childbirth twice, and 15 patients (18.8\%) three times, and 10 patients (12.5\%) once. For surgical procedures, 9 patients (11.3\%) received total hysterectomy, 32 patients $(40.0 \%)$ modified radical hysterectomy and 39 patients $(48.8 \%)$ radical hysterectomy. For history of postoperative multidisciplinary treatments, 58 patients $(72.5 \%)$ reported it, and 14 patients (17.5\%) received radiotherapy, 42 patients $(52.5 \%)$ chemotherapy and 2 patients $(2.5 \%)$ CCRT. For PS, the large majority, 40 patients (50.0\%) answered with " 0 ", (patients had no problem in their daily life as usual), and 38 patients (47.5\%) answered with " 1 " (Restricted in physically strenuous activity but ambulatory and able to carry out work of a light or sedentary nature, e.g., light house work, office work" " 0 " and " 1 " accounted for a very large proportion. Two patients (2.5 patients) scored "2" (Ambulatory and capable of all self-care but unable to carry out any work activities. Up and about more than $50 \%$ of waking hours)." For preoperative and postoperative incontinence, 42 patients (52.5\%) answered with "No experience" whereas 38 patients $(47.5 \%)$ answered with "Experienced". And for measures against incontinence the patients answered that 16 patients use sanitary pad, 15 patients incontinence control pad, 4 patients liner, 2 patients incontinent underpants. Only 1 patient practiced pelvic floor muscle exercise which is considered effective against incontinence whereas 7 patients had no measures (including open-ended questions and multiple answers).

\section{Actual results of CLSS in the survey population (Table 3)}

On daytime urinary frequency 35 patients (43.8\%) answered with “ $\leq 7$ times", 45 patients (56.3\%) " 8 to 9 times" and 0 patients " $\geq 10$ 
Table 1. Basic attributes of survey population.

\begin{tabular}{|c|c|c|c|}
\hline Item & Total & & \\
\hline Age (Mean \pm S.D. range) & $54.96 \pm 11.49(33-78)$ & & \\
\hline Age Category & & $\mathrm{N}$ & $(\%)$ \\
\hline$<50$ y.o. & & 28 & $(35.0 \%)$ \\
\hline 50-69 у.о. & & 43 & $(53.8 \%)$ \\
\hline$\geq 70$ y.o. & & 9 & $(11.3 \%)$ \\
\hline Name of disease & & & \\
\hline Cervical cancer & & 29 & $(36.3 \%)$ \\
\hline Uterine corpus cancer & & 28 & $(35.0 \%)$ \\
\hline Ovarian cancer & & 20 & $(25.0 \%)$ \\
\hline Other cancer & & 3 & $(3.8 \%)$ \\
\hline BMI & $23.55 \pm 5.47(12.0-42.5)$ & & \\
\hline Lean $(\leq 18.4)$ & & 14 & $(17.5 \%)$ \\
\hline Normal (15.0-24.9) & & 39 & $(48.8 \%)$ \\
\hline Obese $(\geq 25.0)$ & & 27 & $(33.8 \%)$ \\
\hline Childbirth experience & & & \\
\hline No experience & & 23 & $(28.8 \%)$ \\
\hline Experienced & & 57 & $(71.3 \%)$ \\
\hline Operative procedure & & & \\
\hline ATH & & 9 & $(11.3 \%)$ \\
\hline Modified radical hysterectc & & 32 & $(40.0 \%)$ \\
\hline Radical hysterectomy & & 39 & $(48.8 \%)$ \\
\hline History of multidisciplinar & eatment & & \\
\hline Not experienced & & 22 & $(27.5 \%)$ \\
\hline Experienced & & 58 & $(72.5 \%)$ \\
\hline Details of multidisciplinary & eatment & & \\
\hline Radiotherapy & & 14 & $(17.5 \%)$ \\
\hline Chemotherapy & & 42 & $(52.5 \%)$ \\
\hline CCRT & & 2 & $(2.5 \%)$ \\
\hline Ope only & & 22 & $(27.5 \%)$ \\
\hline
\end{tabular}

S.D.:Standard deviation

Table 2. Presence of preoperative urinary incontinence and measures taken in the survey population

\begin{tabular}{|l|l|l|}
\hline Item & Total & \multicolumn{2}{|l|}{} \\
\hline Preoperative urinary incontinence & $\mathrm{N}$ & $(\%)$ \\
\hline Not experienced & 42 & $-52.50 \%$ \\
\hline Experienced & 38 & $-47.50 \%$ \\
\hline Breakdown of measures for incontinence & Free answer & \\
\hline & $\mathrm{N}$ & \\
\hline Sanitary pad & 16 & \\
\hline Incontinence pad & 15 & \\
\hline Liner & 4 & \\
\hline Incontinence underpants & 2 & \\
\hline Pelvic floor muscle exercise & 1 & \\
\hline Nothing & 7 & \\
\hline
\end{tabular}

times." 43 patients (53.8\%; highest number) answered that nighttime voiding was "Once", followed by " 0 times" by 37 patients $(46.3 \%)$. For lower urinary tract symptoms, 56 patients $(70.0 \%)$ experienced stress incontinence and 43 patients (53.8\%) had slow urine stream, accounting for more than a half of the population. Other urinary incontinence symptoms were experienced by less than half of the population. For QOL affected by micturition disorders, the predominant number of 62 patients (77.5\%) answered with "Dissatisfied", 12 patients $(15.0 \%)$ "Neither", and 6 patients "Satisfied" (7.5\%).

3. Actual results on surgical procedures, history of multidisciplinary treatments, multidisciplinary treatments, basic attributes, age, BMI, childbirth experience and preoperative and postoperative incontinence (Table 4)
In the age category, for history of surgical procedures in $\geq 70$-yearold population 2 patients $(2.5 \%)$ answered with total hysterectomy, 3 patients (3.8\%) modified radical hysterectomy, 4 patients $(5.0 \%)$ radical hysterectomy. In $<50$-year-old population, 6 patients $(7.5 \%)$ answered with total hysterectomy, 6 patients $(7.5 \%)$ modified radical hysterectomy, and 16 patients $(20.0 \%$, significantly high number) radical hysterectomy. Thus the latter demonstrates the significant predominance. No significant differences were noted for the other items, i.e., BMI, childbirth experience and preoperative and postoperative incontinence. Moreover, no significant differences were noted in age category, BMI, childbirth experience or preoperative and postoperative incontinence in history of multidisciplinary treatments or therapeutic approach of multidisciplinary treatments.

4. Surgical procedures, history of multidisciplinary treatments, therapeutic approach of multidisciplinary treatments and actual results of CLSS (Table 5)

No significant differences were found in surgical procedures and daytime or nighttime urinary frequencies, lower urinary tract symptom, or QOL relating to voiding symptoms. For history of multidisciplinary treatments and dysuria of CLSS, 17 patients $(21.3 \%)$ without multidisciplinary treatments and 58 patients (72.5\%) with multidisciplinary treatments answered with "No urethral pain". This demonstrated significantly lower incidence of dysuria in patients with

Table 3. CLSS in survey population

\begin{tabular}{|c|c|c|}
\hline \multicolumn{3}{|c|}{ Daytime urinary frequency } \\
\hline$\leq 7$ times & 35 & -43.8 \\
\hline 8-9 times & 45 & -56.3 \\
\hline$\geq 10$ times & 0 & 0 \\
\hline \multicolumn{3}{|c|}{ Nighttime urinary frequency } \\
\hline None & 37 & -46.3 \\
\hline Once & 43 & -53.8 \\
\hline Twice or more & 0 & 0 \\
\hline \multicolumn{3}{|l|}{ Urinary urgency } \\
\hline No experience & 51 & -63.8 \\
\hline Experienced & 29 & -36.3 \\
\hline \multicolumn{3}{|c|}{ Urge incontinence } \\
\hline No experience & 50 & -62.5 \\
\hline Experienced & 30 & -37.5 \\
\hline \multicolumn{3}{|c|}{ Stress incontinence } \\
\hline No experience & 24 & -30 \\
\hline Experienced & 56 & -70 \\
\hline \multicolumn{3}{|c|}{ Slow urine stream } \\
\hline No experience & 37 & -46.3 \\
\hline Experienced & 43 & -53.8 \\
\hline \multicolumn{3}{|c|}{ Abdominal straining during voiding } \\
\hline No experience & 42 & -52.5 \\
\hline Experienced & 38 & -47.5 \\
\hline \multicolumn{3}{|c|}{ Feeling of residual urine } \\
\hline No experience & 53 & -66.3 \\
\hline Experienced & 27 & -33.8 \\
\hline \multicolumn{3}{|c|}{ Lower abdominal pain } \\
\hline No experience & 73 & -91.3 \\
\hline Experienced & 7 & -8.8 \\
\hline \multicolumn{3}{|l|}{ Urethral pain } \\
\hline No experience & 75 & -93.8 \\
\hline Experienced & 5 & -6.3 \\
\hline \multicolumn{3}{|l|}{ Voiding QOL } \\
\hline Satisfied & 6 & -7.5 \\
\hline Neither & 12 & -15 \\
\hline Dissatisfied & 62 & -77.5 \\
\hline
\end{tabular}


Table 4. Operative procedure, History of multidisciplinarytreatment, Details of multidisciplinarytreatment and Basic attributes

\begin{tabular}{|c|c|c|c|c|c|c|c|c|c|c|c|c|c|c|c|c|c|c|c|c|c|c|c|c|}
\hline \multirow[t]{2}{*}{ Item } & \multicolumn{8}{|c|}{ Operative procedure } & \multicolumn{6}{|c|}{ History of multidisciplinary treatment } & \multicolumn{10}{|c|}{ Details of multidisciplinary treatment } \\
\hline & \multicolumn{2}{|c|}{$\begin{array}{l}\text { Simple } \\
\text { hysterectomy }\end{array}$} & \multicolumn{2}{|c|}{\begin{tabular}{|l|} 
Modified \\
radical \\
hysterectomy
\end{tabular}} & \multicolumn{2}{|c|}{$\begin{array}{l}\text { Radical } \\
\text { hysterectomy }\end{array}$} & & & \multirow{2}{*}{\multicolumn{2}{|c|}{\begin{tabular}{|l|}
$\begin{array}{l}\text { No } \\
\text { experience } \\
(\mathrm{n}=22)\end{array}$ \\
$53.18 \pm 11.39$ \\
\end{tabular}}} & \multirow{2}{*}{\multicolumn{2}{|c|}{\begin{tabular}{|l}
$\begin{array}{l}\text { Experienced } \\
(\mathrm{n}=58)\end{array}$ \\
$55.64 \pm 11.55$
\end{tabular}}} & t value & & \multicolumn{2}{|c|}{ Radiotherapy } & \multicolumn{2}{|c|}{ Chemotherapy } & \multicolumn{2}{|c|}{ CCRT } & \multicolumn{2}{|c|}{ Ope only } & \\
\hline Age & & & & & & & & & & & & & -0.852 & & & & & & & & & & & \\
\hline BMI value & & & & & & & & & \multicolumn{2}{|c|}{$23.07 \pm 5.20$} & \multicolumn{2}{|c|}{$23.73 \pm 5.16$} & -0.48 & & & & & & & & & & \multirow[b]{2}{*}{$\mathrm{X} 2$} & \\
\hline \multicolumn{7}{|l|}{ Age Category } & $\mathrm{X} 2$ & $\mathrm{p}$ & & & & & $\mathrm{X} 2$ & $\mathrm{p}$ & & & & & & & & & & $\mathrm{p}$ \\
\hline$<50$ y.o. & 6 & -7.5 & 6 & -7.5 & 16 & -20 & & & 9 & -11.3 & 19 & -23.8 & & & 8 & -10 & 10 & -12.5 & 1 & -1.3 & 9 & -11.3 & & \\
\hline $50-69$ y.o. & 1 & -1.3 & 23 & -28.8 & 19 & -23.8 & 11.67 & $*$ & 12 & -15 & 31 & -38.8 & 1.51 & n.s & 5 & -6.3 & 25 & -31.3 & 1 & -1.3 & 12 & -15 & 7.33 & n.s \\
\hline$\geq 70$ y.o. & 2 & -2.5 & 3 & -3.8 & 4 & -5 & & & 1 & -1.3 & 8 & -10 & & & 1 & -1.3 & 7 & -8.8 & 0 & 0 & 1 & -1.3 & & \\
\hline \multicolumn{25}{|c|}{ BMI Category } \\
\hline Lean & 3 & -3.8 & 8 & -10 & 3 & -3.8 & & & 3 & -3.8 & 11 & -13.8 & 2.73 & n.s & 3 & -3.8 & 8 & -10 & 0 & 0 & 3 & -3.8 & & n.s \\
\hline Normal & 4 & -5 & 14 & -17.5 & 21 & -26.3 & 5.53 & n.s & 14 & -17.5 & 25 & -31.3 & & & 7 & -8.8 & 17 & -21.3 & 1 & -1.3 & 14 & -17.5 & 3.93 & n.s \\
\hline Obese & 2 & -2.5 & 10 & -12.5 & 15 & -18.8 & & & 5 & -6.3 & 22 & -27.5 & & & 4 & -5 & 17 & -21.3 & 1 & -1.3 & 5 & -6.3 & & \\
\hline \multicolumn{25}{|c|}{ Labor experience } \\
\hline $\begin{array}{l}\text { Not } \\
\text { experienced }\end{array}$ & 3 & -3.8 & 7 & -8.8 & 13 & -16.3 & 1.23 & n.s & 4 & -5 & 19 & -23.8 & 1.65 & n.s & 5 & -6.3 & 13 & -16.3 & 1 & -1.3 & 4 & -5 & 0.077 & n.s \\
\hline Experienced & 6 & -7.5 & 25 & -31.3 & 26 & -32.5 & & & 18 & -22.5 & 39 & -48.8 & & & 9 & -11.3 & 29 & -36.3 & 1 & -1.3 & 18 & -22.5 & & \\
\hline \multicolumn{25}{|c|}{ Preoperative urinary incontinence } \\
\hline $\begin{array}{l}\text { Not } \\
\text { experienced }\end{array}$ & 7 & -8.8 & 14 & -17.5 & 21 & -26.3 & 5.53 & n.s & 12 & -15 & 30 & -37.5 & 0.05 & n.s & 7 & -8.8 & 22 & -27.5 & 1 & -1.3 & 12 & -15 & 3.93 & n.s \\
\hline Experienced & 2 & -2.5 & 18 & -22.5 & 18 & -22.5 & & & 10 & -12.5 & 28 & -35 & & & 7 & -8.8 & 20 & -25 & 1 & -1.3 & 10 & -12.5 & & \\
\hline
\end{tabular}

$* \mathrm{p}<0.05$

multidisciplinary treatments $(\chi 2=14.06, \mathrm{p}<0.001)$. For therapeutic approach of multidisciplinary treatments and lower abdominal pain of CLSS category, 42 patients $(52.5 \%)$ on chemotherapy answered with "No experience" in lower abdominal and urethral pain, whereas 0 patients $(0.0 \%)$ "Experienced." It demonstrated a significant difference among therapeutic approaches of multidisciplinary treatments (lower abdominal pain, $\chi 2=11.27, \mathrm{p}<0.01)$ (dysuria, $(\chi 2=14.06, \mathrm{p}<0.003)$. In the other CLSS items no significant differences were noted for history of multidisciplinary treatments and therapeutic approaches of multidisciplinary treatments.

\section{Discussion}

\section{Associations between basic attributes and surgical procedures}

Results from precedent research suggested that even in the 30 to 50 -year-old females 20 to $50 \%$ of them experience urinary incontinence $[8,9]$, which is mostly stress incontinence. The primary causes may include parturition, intrapelvic surgery and aging. Stress incontinence can be primarily attributed to e.g. cystoptosis, loosening of the pelvic floor muscle groups, and relaxed urethral sphincter [10], presenting complex pathological condition. In the survey population, about $60 \%$ of patients were $\geq 50$-year-old age, $70 \%$ of them experienced childbirth, and patients have undergone radical hysterectomy, the primary causes of micturition disorders. Nonetheless, from the results of CLSS 30 to $50 \%$ of patients reported urinary urgency, urge incontinence, slow urine stream, abdominal straining during voiding and feeling of residual urine, and some of them experienced not only stress incontinence but also multiple lower urinary tract symptoms. As measures against micturition disorders, Clinical Guideline for Female Lower Urinary Tract Symptoms [10] publicly recommends that pelvic floor muscle exercise can be the first-line treatment for patients with stress incontinence. However, in this research only one patient practiced the exercise and it may suggest the lack of explanation on the effectiveness and guidance of pelvic floor muscle exercise to patients. Moreover, a guideline points out low patient compliance to pelvic floor muscle exercise and the need for motivating patients to do the exercise
[11]. In this sense, the important things are instructions to improve micturition disorders, involving comprehensive cares combining lifestyle guidance, psychological supports and physical therapy in addition to improvements in functional aspects. Patients can realize the effects of treatments and can practice self-care thereby.

\section{Associations between history and therapeutic approach of multidisciplinary treatments}

The result of the present research did not correspond to a precedent study that considered radiotherapy in multidisciplinary treatments as a factor contributing to micturition disorders [12]. This might have been influenced by the inclusion of s small number of patients who underwent CCRT. Nevertheless, radiotherapy following radical hysterectomy reduced bladder compliance and increased residual urine, which may contribute to micturition disorders [12] and thereby sometimes the onset of micturition disorders may be induced after the treatment.

As cancer screening becomes more common, the prevalence of gynecologic cancers has increased, and an increase in cancer patients may lead to increases in the number of interventions with radiotherapy and CCRT. The more surgical technology advances, the less micturition disorders and neuropathic bladder may develop, which are postoperative complications. Nevertheless, radiotherapy is a contributing factor of micturition disorders. This may warrant that data on voiding should be collected from patients treated with radiotherapy in a meticulous manner. And when changes in voiding patterns are detected providing guidance on voiding diary, complete assessments on in symptomatic impairment patterns in urinary tract function and thereby providing adequate cares and long-term supports may be required.

Despite the fact that micturition disorders following cancer treatments can reduce QOL, contribute to burdens by operations and affect physical and mental health of female patients significantly, the current situation about embarrassment of female patients tends to be uncertain. Nurses need to collaborate with gynecologists, urologists and pharmacists as a team to provide treatments, nursing cares and 
Table 5. Operative procedure, Hiatory of multidisciplinary treatment, Deatails of multidisciplinary treatment and CLSS

\begin{tabular}{|c|c|c|c|c|c|c|c|c|c|c|c|c|c|c|c|c|c|c|c|c|c|c|c|c|}
\hline & \multicolumn{8}{|c|}{ Operative procedure } & \multicolumn{5}{|c|}{$\begin{array}{c}\text { History of multidisciplinary } \\
\text { treatment }\end{array}$} & \multicolumn{9}{|c|}{ Details of multidisciplinary treatment } & \multirow[b]{2}{*}{$\mathrm{X} 2$} & \multirow[b]{2}{*}{$\mathrm{p}$} \\
\hline & \multicolumn{2}{|c|}{$\begin{array}{c}\text { Simple } \\
\text { hysterectomy }\end{array}$} & \multicolumn{2}{|c|}{\begin{tabular}{|c|} 
Modified \\
radical \\
hysterectomy
\end{tabular}} & \multicolumn{2}{|c|}{$\begin{array}{c}\text { Radical } \\
\text { hysterectomy }\end{array}$} & $\mathrm{X} 2$ & $\mathrm{p}$ & \multicolumn{2}{|c|}{$\begin{array}{c}\text { No } \\
\text { experience }\end{array}$} & \multicolumn{2}{|c|}{ Experienced } & $\mathrm{X} 2$ & $\mathrm{p}$ & \multicolumn{2}{|c|}{ Radiotherapy } & \multicolumn{2}{|c|}{ Chemotherapy } & \multicolumn{2}{|c|}{ CCRT } & \multicolumn{2}{|c|}{ Ope only } & & \\
\hline \multicolumn{25}{|c|}{ Daytime urinary frequency } \\
\hline$\leq 7$ times & 7 & -8.8 & 13 & -16.3 & 15 & -18.8 & & & 11 & -13.8 & 24 & -30 & & & 6 & -7.5 & 17 & -21.3 & 1 & -1.3 & 11 & -13.8 & & \\
\hline 8-9 times & 2 & -2.5 & 19 & -23.8 & 24 & -30 & 4.8 & n.s & 11 & -13.8 & 34 & -42.5 & 0.48 & n.s & 8 & -10 & 25 & -31.3 & 1 & -1.3 & 11 & -13.8 & 0.56 & n.s \\
\hline$\geq 10$ times & 0 & 0 & 0 & 0 & 0 & 0 & & & 0 & 0 & 0 & 0 & & & 0 & 0 & 0 & 0 & 0 & 0 & 0 & 0 & & \\
\hline \multicolumn{25}{|c|}{ Nighttime urinary frequency } \\
\hline 0 times & 4 & -5 & 14 & -17.5 & 19 & -23.8 & & & 9 & -11.3 & 28 & -35 & & & 9 & -11.3 & 18 & -22.5 & 1 & -1.3 & 9 & -11.3 & & \\
\hline Once & 5 & -6.3 & 18 & -22.5 & 20 & -25 & 0.18 & n.s & 13 & -16.3 & 30 & -37.5 & 0.34 & n.s & 5 & -6.3 & 24 & -30 & 1 & -1.3 & 13 & -16.3 & 2.29 & n.s \\
\hline Twice and more & 0 & 0 & 0 & 0 & 0 & 0 & & & 0 & 0 & 0 & 0 & & & 0 & 0 & 0 & 0 & 0 & 0 & 0 & 0 & & \\
\hline \multicolumn{25}{|c|}{ Urinary urgency } \\
\hline No experience & 8 & -10 & 17 & -21.3 & 26 & -32.5 & 4.16 & n.s & 11 & -13.8 & 40 & -50 & 0.24 & n.s & 11 & -13.8 & 28 & -35 & 1 & -1.3 & 11 & -13.8 & 3.44 & n.s \\
\hline Experienced & 1 & -1.3 & 15 & -18.8 & 13 & -16.3 & & & 11 & -13.8 & 18 & -22.5 & & & 3 & -3.8 & 14 & -17.5 & 1 & -1.3 & 11 & -13.8 & & \\
\hline \multicolumn{25}{|c|}{ Urge incontinence } \\
\hline No experience & 7 & -8.8 & 22 & -27.5 & 21 & -26.3 & 2.67 & n.s & 16 & -20 & 34 & -42.5 & 1.35 & n.s & 8 & -10 & 25 & -31.3 & 1 & -1.3 & 16 & -20 & 1.44 & n.s \\
\hline Experienced & 2 & -2.5 & 10 & -12.5 & 18 & -22.5 & & & 6 & -7.5 & 24 & -30 & & & 6 & -7.5 & 17 & -21.3 & 1 & -1.3 & 6 & -7.5 & & \\
\hline & & & & & & & & & & Stress in & contil & ience & & & & & & & & & & & & \\
\hline No experience & 5 & -6.3 & 9 & -11.3 & 10 & -12.5 & 3.2 & $\mathrm{n} . \mathrm{s}$ & 7 & -8.8 & 17 & -21.3 & 0.048 & n.s & 4 & -5 & 13 & -16.3 & 0 & 0 & 7 & -8.8 & 0.92 & n.s \\
\hline Experienced & 4 & -5 & 23 & -28.8 & 29 & -36.3 & & & 15 & -18.8 & 41 & -51.3 & & & 10 & -12.5 & 29 & -36.3 & 2 & -2.5 & 15 & -18.8 & & \\
\hline & & & & & & & & & & Slow ur & rine st & eam & & & & & & & & & & & & \\
\hline No experience & 7 & -8.8 & 15 & -18.8 & 15 & -18.8 & 4.55 & n.s & 13 & -16.3 & 24 & -30 & 2.01 & $\mathrm{n} . \mathrm{s}$ & 3 & -3.8 & 20 & -25 & 1 & -1.3 & 13 & -16.3 & 4.97 & n.s \\
\hline Experienced & 2 & -2.5 & 17 & -21.3 & 24 & -30 & & & 9 & -11.3 & 34 & -42.5 & & & 11 & -13.8 & 22 & -27.5 & 1 & -1.3 & 9 & -11.3 & & \\
\hline & & & & & & & & $\mathrm{Ab}$ & domir & nal strair & ning $d$ & uring vo & iding & & & & & & & & & & & \\
\hline No experience & 7 & -8.8 & 17 & -21.3 & 18 & -22.5 & 2.94 & n.s & 11 & -13.8 & 31 & -38.8 & 0.07 & $\mathrm{n} . \mathrm{s}$ & 4 & -5 & 26 & -32.5 & 1 & -1.3 & 11 & -13.8 & 4.76 & n.s \\
\hline Experienced & 2 & -2.5 & 15 & -18.8 & 21 & -26.3 & & & 11 & -13.8 & 27 & -33.8 & & & 10 & -12.5 & 16 & -20 & 1 & -1.3 & 11 & -13.8 & & \\
\hline & & & & & & & & & & eling of & residu & al urine & & & & & & & & & & & & \\
\hline No experience & 8 & -10 & 22 & -27.5 & 23 & -28.8 & 3.07 & n.s & 13 & -16.3 & 40 & -50 & 0.69 & n.s & 8 & -10 & 31 & -38.8 & 1 & -1.3 & 13 & -16.3 & 2.33 & n.s \\
\hline Experienced & 1 & -1.3 & 10 & -12.5 & 16 & -20 & & & 9 & -11.3 & 18 & -22.5 & & & 6 & -7.5 & 11 & -13.8 & 1 & -1.3 & 9 & -11.3 & & \\
\hline & & & & & & & & & & ower abc & domin & al pain & & & & & & & & & & & & \\
\hline No experience & 9 & -11.3 & 29 & -36.3 & 35 & -43.8 & 0.99 & n.s & 18 & -22.5 & 55 & -68.8 & 3.38 & n.s & 12 & -15 & 42 & -52.5 & 1 & -1.3 & 18 & -22.5 & 11.27 & $*$ \\
\hline Experienced & 0 & 0 & 3 & -3.8 & 4 & -5 & & & 4 & -5 & 3 & -3.8 & & & 2 & -2.5 & 0 & 0 & 1 & -1.3 & 4 & -5 & & \\
\hline & & & & & & & & & & Ureth & aral pa & & & & & & & & & & & & & \\
\hline No experience & 9 & -11.3 & 28 & -35 & 38 & -47.5 & 3.63 & n.s & 17 & -21.3 & 58 & -72.5 & 14.06 & $* *$ & 14 & -17.5 & 42 & -52.5 & 2 & -2.5 & 17 & -21.3 & 14.06 & $* * *$ \\
\hline Experienced & 0 & 0 & 4 & -5 & 1 & -1.3 & & & 5 & -6.3 & 0 & 0 & & & 0 & 0 & 0 & 0 & 0 & 0 & 5 & -6.3 & & \\
\hline & & & & & & & & & & Voidi & ing QC & & & & & & & & & & & & & \\
\hline Satisfied & 2 & -2.5 & 2 & -2.5 & 2 & -2.5 & & & 2 & -2.5 & 4 & -5 & & & 1 & -1.3 & 3 & -3.8 & 0 & 0 & 2 & -2.5 & & \\
\hline Neither & 2 & -2.5 & 5 & -6.3 & 5 & -6.3 & 4.07 & n.s & 5 & -6.3 & 7 & -8.8 & 1.65 & n.s & 1 & -1.3 & 5 & -6.3 & 1 & -1.3 & 5 & -6.3 & 4.21 & n.s \\
\hline Dissatisfied & 5 & -6.3 & 25 & -31.3 & 32 & -40 & & & 15 & -18.8 & 47 & -58.8 & & & 12 & -15 & 34 & -42.5 & 1 & -1.3 & 15 & -18.8 & & \\
\hline
\end{tabular}

Chi-squared test: ${ }^{*} \mathrm{p}<0.05,{ }^{*} \mathrm{p}<0.01, * * * \mathrm{p}<0.001$

follow-up including efficient and effective educations and guidance for micturition disorders and thereby strive for patients' QOL maintenance and improvement.

\section{Conclusions}

The current status of micturition disorders in patients who underwent gynecologic cancer treatments shows a trend toward more patients with stress incontinence and slow urine stream as micturition disorders. But for such disorders devices such as incontinence pad are often used, and only about $1 \%$ of the population was practicing pelvic floor muscle exercise. Moreover, no association was noted between lower urinary tract symptoms and surgical types, history of multidisciplinary treatments and multidisciplinary care type. However, as many as $80 \%$ of the patients answered with "Dissatisfied" for QOL relating to voiding symptoms. In postoperative patients who will undergo multidisciplinary treatments for gynecologic cancer, it is expected that micturition disorders can be a factor contributing to lower QOL. And future researches need to investigate exhaustively elements including medical history and medications which may potentially contribute to micturition disorders.

\section{Acknowledgment}

The author would like to thank all the patients who cooperated with this present survey and the lecturers of the Gynecology course at Fukushima Medical University. This study received a research grant for Cancer Nursing Care A from the Yasuda Memorial Medical Foundation for 2016.

\section{Reference}

1. Zullo MA, Manci N, Angioli R, Muzii L, Panici PB (2003) Vesical Dysfunction after Radical Hysterectomy for Cervical Cancer: A Critical Review. Crit Rev Oncol Hematol 48: 287-293. [Crossref]

2. Sakuragi N (2006) Radical hysterectomy and functional conservations. $J$ Obstetr Gynaecol Res 93 : 371-680.

3. Egashira N, Kawashiri T, Oishi R (2010) The current state of the drugs for the treatment of peripheral neuropathy induced by anticancer drugs. Nihon Yakurigaku Zasshi 136(5):275-9. [Crossref] 
Inoue M (2017) Survey on micturition disorders, surgical procedures and therapeutic approaches in patients treated for gynecologic cancers in clinical settings

4. Inoue M, Sato W (2012) Actual Status of and Factors Related to the Quality of Life of Patients in the Recovery Phase after Surgical Procedures for Gynecological Cancer. Jpn Soc Canc Nurs 26: 14-22.

5. Homma Y, Yoshida M, Yamanishi T, Gotoh M (2008) Core Lower Urinary Tract Symptom Score (CLSS) questionnaire: A reliable tool in the overall assessment of lower urinary tract symptoms. Int J Urol 15: 816-820. [Crossref]

6. RichHill Medical Inc (2011) Clinical Guideline for Benign Prostatic Hyperplasia. Int J Urol.

7. Fujimura T, Kume H, Tsurumaki Y, Yoshimura Y, Hosoda C, et al. (2011) Core lower urinary tract symptom score (CLSS) for the assessment of female lower urinary tract symptoms: a comparative study. Int J Urol 18: 778-784.

8. Kamezaki A, Tanaka M (2015) The clinical picture of urinary incontinence in Japanese females and association between vaginal pressure and urinary incontinence. Yamaguchi Igaku 64: 79-85.
9. Kurokawa S, Inoue K, Nakano O (2002) Investigation on frequency and background factors of female urinary incontinence. Monthly community med 16: 401-405.

10. Takahashi S, Takei M, Nishizawa O, Yamaguchi O, Kato K (2013) Panel for Preparation of Japanese Clinical Guideline for Female Lower Urinary Tract Symptoms. Low Urin Tract Symptoms 8: 5-29. [Crossref]

11. Research Panel on Standardized Therapy in Urology Area (edition): EBM-based Urinary Incontinence Treatment Guideline. Jiho, Tokyo, 2004.

12. Hashimoto M, Suzuki M, Kinoshita K (2006) Variability of bladder dysfunction in post radical hysterectomy effect of pelvic autonomic nerve preservation with/without postoperative radiation therapy. Juntendo Igaku 52: 588-595. [Crossref]

Copyright: @2017 Inoue M. This is an open-access article distributed under the terms of the Creative Commons Attribution License, which permits unrestricted use, distribution, and reproduction in any medium, provided the original author and source are credited. 